\section{The real threat from antibiotics}

SIR - In your leading article "Distrust in genetically altered foods" (Nature 383, 559; 1996) you side with the British Advisory Committee on Novel Foods and Processes (ACNFP) on the issue of an ampicillin resistance gene in some strains of transgenic corn. The ACNFP had decided that the ampicillin resistance gene in the transgenic corn posed an "unacceptable risk" because of the possibility that it might be transferred from the corn genome into the genomes of bacteria found in the intestinal tracts of animals and humans.

Following the ACNFP decision, a group of experts was convened in Talloires, France, in September to consider the issue. The meeting was convened by the Foundation for Nutritional Advancement, a private foundation associated with Tufts University in Massachusetts, and was attended by a small group of microbiologists and food safety experts from the United States, the United Kingdom and several other European countries. The unanimous conclusion of this group, of which I was a member, was that the ampicillin resistance gene in the transgenic corn posed no significant health hazard to humans or animals.

This conclusion was based not only on the fact that the probability that the gene would be transferred from corn to bacteria was negligible, but also on the fact that, even if such a transfer occurred, it would have no clinical impact. The ampicillin gene in the transgenic corn strain is the bla gene that is present on pUC19 and other plasmids used by molecular biologists. This gene, which encodes a $\beta$-lactamase, was originally cloned from a clinical strain isolated in the 1960s. This type of resistance gene poses no clinical problems today because there are many antibiotic formulations that easily control strains producing this type of $\beta$-lactamase.

By contrast, the $\beta$-lactamase genes that are currently causing problems in hospitals are modern genes that have evolved extensively during the past few decades to the point where they confer resistance not only to a wide variety of $\beta$-lactam antibiotics but also to $\beta$-lactamase inhibitors that have been used to 'recycle' antibiotics like ampicillin. Additionally, a new type of resistance to $\beta$-lactam antibiotics that is different from $\beta$-lactamases (mutant penicillin-binding proteins) is causing resistance problems in the Gram-positive bacteria.

Finding the old-style bla gene in a hospital isolate today would evoke yawns rather than cries of distress. Moreover, such a gene would most likely have been transferred from other hospital bacteria that carry the gene on transmissible genetic elements. The ACNFP failed to consider the clinical impact of a transfer of the bla gene from corn to bacteria in its analysis. Instead, it seemed to have assumed that all antibiotic resistance genes are equally dangerous, which is definitely not the case.

Unfortunately, Nature chose to focus attention on the extremely minor threat posed by transgenic corn while ignoring another European regulatory decision that is far more likely to have an impact on human health. In May, only a few months before the ACNFP decision, the European Scientific Committee for Animal Nutrition (SCAN) approved the continued use of the antibiotic avoparcin as a feed additive for farm animals. Avoparcin is an analogue of vancomycin and is known to select for resistance genes that confer resistance to vancomycin. Vancomycin resistance in Grampositive bacteria is one of the most serious resistance problems currently encountered in large US and European hospitals, where vancomycin is sometimes the only antibiotic left that is effective against multiply resistant strains of Staphylococcus aureus.

Certainly, there is room for argument about the extent to which feeding avoparcin to farm animals - and the concomitant exposure of farm workers and their bacteria to antibiotic selection - might contribute to an increased incidence of vancomycin-resistant clinical isolates, but this seems to me to be a far more serious issue than the remote possibility of transfer of an ampicillin resistance gene from corn to bacteria.

In the last paragraph of the leading article, you expressed concern about "deep-rooted cultural fears of genetic manipulation" on the part of the public and stressed the importance of generating congenetically engineered foods. I do not know whether, as you contend, the seed companies are behaving in a way that increases consumer distrust of their product. I do know, however, that we as scientists need to do a better job of communicating scientific issues to the public.

In my vicw your leading article is a case study in how misguided scientific emphasis can help to increase public confusion and anxiety about genetic engineering and its products. By choosing to give precious space to what is at best a very minor safety concern, while ignoring the real antibiotic resistance problems - such as the continued abuse and overuse of antibiotics by physicians, over-the-counter sale of antibiotics, and use of antibiotics in animal feed Nature is sending the wrong message to the public about the forces that are driving the increase in antibiotic resistance.

\section{Abigail Salyers}

Department of Microbiology,

University of Illinois,

Urbana, Illinois 61801, USA

e-mail: abigail_salyers@qms1.life.uiuc.edu sumer trust and confidence in the new

\section{Act now on $\mathrm{CO}_{2}$}

SIR - The main theme of the study on atmospheric $\mathrm{CO}_{2}$ you published earlier this year by Wigley et al. was that "[p]athways involving modest reductions below a 'business-as-usual' (BAU) scenario in the early years followed by sharper reductions later on were found to be less expensive than those involving substantial reductions in the short term"'. The study also argued that "an immediate departure from the BAU path is not necessarily required for concentration targets of 450 p.p.m.v. and above".

Wigley is surely correct in stating that the Wigley et al.' study does not itself advocate a delay in cutting carbon dioxide emissions ${ }^{2}$.

Precautionary action starting now is advocated by various organizations, including the World Energy Council. The reasons include lead times, building up technology knowhow and capacity building more generally, financing requirements, and the gradual retirement of the existing capital stock. The potential for increasing energy efficiency, accelerating non-fossil fuel availability and cleaner fossil fuel provision and use is immense. Even action now will, in reality, bring only modest reductions below a BAU scenario in the early years. The results will snowball. The problem now is that not even the industrialized countries are, in aggregate, reducing their carbon dioxide emissions - as the chart you recently produced amply demonstrated ${ }^{2}$.

\section{Michael Jefferson}

World Energy Council, 34 St. James's Street, London SW1A $1 H D$, UK

1. Wigley, T. M. L., Richels, R. \& Edmonds, J. A. Nature 379, 240-242 (1996).

2. Masood, E. Nature 382, 103 (1996).

\section{Hooked on Nature}

SIR - Mark Griffiths suggests six components that "need to be fulfilled if a behaviour is to be defined as 'addictive" " (Nature 384, 18; 1996). My scientific activities fulfil all six components, and my weekly reading of Nature fulfils three.

Having experienced signs of withdrawal, ensuing interpersonal conflicts and periods of relapse, I have long suspected this addiction. However, I need to be convinced that it "should be treated no differently from the better known chemically based addictions". Per Södersten

Department of Clinical Neuroscience,

Karolinska Institute,

Novum, S-141 57 Huddinge,

Sweden

\section{corres@nature.com}

Letters submitted for Correspondence should be typed, double-spaced, on one side of the paper only, or e-mailed to corres@nature.com 